\title{
Good function but very high concentrations of cobalt and chromium ions in blood 37 years after metal-on-metal total hip arthroplasy
}

\author{
Per Wretenberg \\ Department of Molecular Medicine \\ and Surgery, Section of Orthopaedics, \\ Karolinska Institute, Karolinska \\ University Hospital, Solna, Stockholm, \\ Sweden
}

\begin{abstract}
This case report describes a patient who had a metal-on-metal hip prosthesis implanted 37 years ago. The hip function and X-ray are presented. The levels of cobalt and chromium ions in blood are analyzed and found to be about 40 times higher than normal. Consequences are discussed.
\end{abstract}

Keywords: hip prosthesis, metal ions

\section{Case report}

In December 2005, an 84-year-old man was transported to the trauma unit at the Karolinska Hospital after a severe accident in which he was run over by a reversing car. At arrival his Glasgow Coma Scale score was 15 and he had multiple costa fractures and pneumothorax and was treated at the intensive care unit for 2 days and was in hospital for additional 5 days before he could be discharged.

At arrival to the emergency department it was noted that he had a scar at the left hip. He had a total hip arthroplasty at the Karolinska Hospital on May 25, 1970 and the prosthesis had worked perfectly ever since. An X-ray showed no evidence of loosening or osteolysis (Figure 1). The prosthesis was a McKee-Farrar metal-on-metal cobalt-chromium alloy hip arthroplasty (Howmedica Limited, London, UK). Since we have an interest in metal-on-metal prosthesis in relation to the metal ion concentration in blood, we decided to measure the concentrations of chromium and cobalt in his blood. The analysis was made with inductively coupled plasma mass spectrometer (ICP-MS) (Moens et al 1995). The chromium concentration was $19.43 \mu \mathrm{g} / \mathrm{L}(0.05-0.48)$ and the cobalt concentration was $22.92 \mu \mathrm{g} / \mathrm{L}(0.03-0.8)$. These levels are about 40 times higher than normal. The patient was otherwise healthy with no problems from internal organs or skin. The hip was completely painless with good range of motion: flexion $85^{\circ}$, extension $0^{\circ}$, internal rotation $5^{\circ}$, external rotation $15^{\circ}$, abduction $30^{\circ}$, and adduction $10^{\circ}$. The creatinin level was slightly increased at $129 \mu \mathrm{mol} / \mathrm{L}$ (ref. <100), but the patient had no clinical sign of renal failure. Other blood samples showed LPK $4.7 \times 10^{9} / 1$ (ref. 3.5-8.8), T-cell count 86\% (ref. 63-88), and normal levels of S-IgG, S-IgA, and S-IgM were found.

\section{Discussion}

Today, the numbers of metal-on-metal implants are increasing rapidly due to the high interest in surface replacement arthroplasty. One side effect of this type of articulation is that metal ions such as cobalt, chromium, manganese, and nickel are released from such articulations and can be found in the proximity of the implant. These heavy metal ions are distributed via the blood stream to distant parenchymal organs (Urban et al 2000)
Correspondence: Per Wretenberg Department of Molecular Medicine Surgery, Section of Orthopaedics, Karolinska University Hospital, Solna, S- 17176 Stockholm, Sweden

Tel +46-8-5I 770000

Email per.wretenberg@karolinska.se 


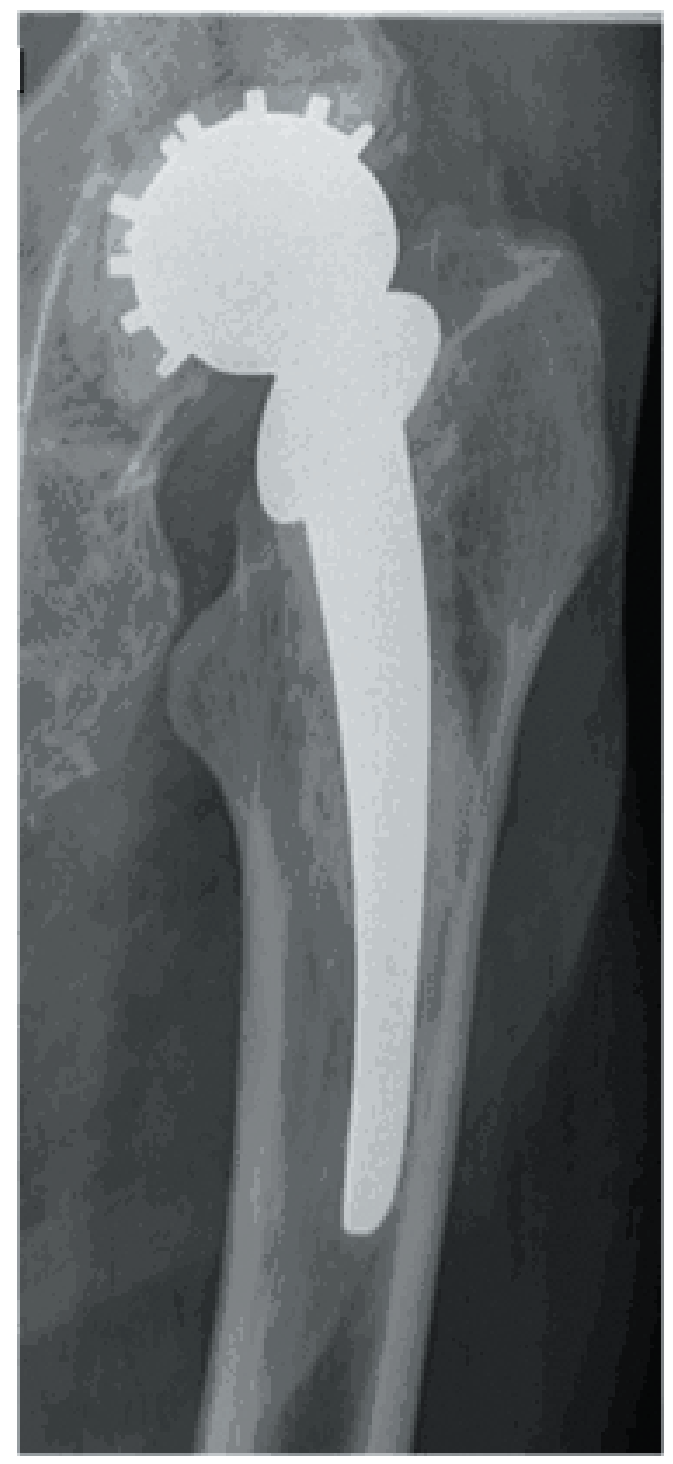

Figure I McKee-Farrar prosthesis 37 years after implantation.

and are subsequently excreted renally. The consequences of metal ion release from orthopedic implants are unclear. It is well known that ions such as nickel and chromium can induce allergic reactions. However, very few reports have shown allergic reactions from metal implants (Niki et al 2005). Several other concerns as lymphocyte-mediated osteolysis (Willert et al 2005), inhibition of osteoblast proliferation and collagen synthesis (Anissian 2002), toxicological considerations (Visuri et al 1996; Signorello et al 2001) and immunological changes (Hart et al 2006) have also been raised. Several studies describe increased levels of metal ions after implantation of a metal-on-metal prosthesis (eg, Masse et al 2003; Ladon et al 2004) and the increased levels have been shown to be up to 10-fold in serum. A 3-fold increase in serum cobalt 20 years after McKee-Farrar prosthesis has been found (Jacobs et al 1996). There are no previous case reports or studies of ion levels 37 years after metal-on-metal implantation. This case indicates that metal ion levels might rise to extreme levels in the very long term for patients with metal-on-metal articulations. Nowadays, since patients who are selected for metal-on-metal prosthesis are mostly young, this might be a future concern. For example, what will happen in cases of renal failure?

\section{Conclusion}

Metal ion concentration after implantation of a metal-on-metal prosthesis can rise to extreme levels in the long run. However, this might not be associated with illness or poor hip function. On the other hand, it is a concern that must be addressed preoperatively.

\section{Disclosure}

The author reports no conflicts of interest in this work.

\section{References}

Anissian L, Stark A, Dahistrand H, et al. 2002. Cobalt ions influence proliferation and function of human osteoblast-like cells. Acta Orthop Scand, 73:369-74.

Hart AJ, Hester T, Sinclair K, et al. 2006. The association between metal ions from hip resurfacing and reduced T-cell counts. $J$ Bone Joint Surg Br, 88:449-54.

Jacobs JJ, Skipor AK, Doorn PF, et al. 1996. Cobalt and chromium concentrations in patients with metal on metal total hip replacements. Clin Orthop Relat Res, (329 Suppl):256-S63.

Ladon D, Doherty A, Newson R, et al. 2004. Changes in metal levels and chromosome aberrations in the peripheral blood of patients after metal-on-metal hip arthroplasty. J Arthroplasty, 19:78-83.

Masse A, Bosetti M, Buratti C, et al. 2003. Ion release and chromosomal damage from total hip prosthesis with metal-on-metal articulation. J Biomed Mater Res, 67:750-7.

Moens L, Vanhaecke J, Riondato R, et al. 1995. Some figures of merit of a new double focusing inductively coupled plasma mass spectrometer. J Anal Spectrom, 10:569-74.

Niki Y. 2005. Screening for symptomatic metal sensitivity: a prospective study of 92 patients undergoing arthroplasty. Biomaterials, 26:1019-26.

Signorello LB, Ye W, Fryzek JP, et al. 2001. Nationwide study of cancer risk among hip replacement patients in Sweden. J Natl Cancer Inst, 93:1405-10.

Urban RM, Jacobs JJ, Tomlinson MJ, et al. 2000. Dissemination of wear particles to the liver, spleen, and abdominal lymph nodes of patients with hip or knee replacement. J Bone Joint Surg Am, 82:457-76.

Visuri T, Pukkala E, Paavolainen P, et al. 1996. Cancer risk after metal on metal and polyethylene on metal total hip arthroplasty. Clin Orthop Relat Res, (329 Suppl):S280-S89.

Willert HG, Buchhorn GH, Fayyazi A, et al. 2005. Metal-on-metal bearings and hypersensitivity in patients with artificial hip joints. A clinical and histomorphological study. J Bone Joint Surg Am, 87:28-36. 